\title{
MAGNITUDE DETERMINATION FOR DEEP-FOCUS EARTHQUAKES*
}

\section{By B. Gutenberg}

IN A RECENT paper (Gutenberg, 1945) the author presented a study of the amplitudes of $\mathrm{P}, \mathrm{PP}$, and $\mathrm{S}$ in shallow earthquakes and gave equations and tables permitting their use in the determination of the magnitude. In the present paper this method is extended to make possible the determination of the magnitude of earthquakes at any given depth.

The magnitude of a shallow earthquake in southern California was defined by Richter (1935) as the logarithm of the maximum trace amplitude expressed in microns with which the standard short-period torsion seismometer would register that shock at an epicentral distance of $100 \mathrm{~km}$. Any definition of the magnitude of a deep-focus shock must lead to values in agreement with this definition for such shocks having a depth of about $18 \mathrm{~km}$. To retain the same definition for all values of $h$ (focal depth) would have the disadvantage that neither the energy, nor the acceleration at the epicenter, nor any other quantity frequently used would be the same for two shocks of the same magnitude originating at different depths. More than that, it would not be possible to arrive empirically at tables or graphs giving the relationship between the magnitude and trace amplitudes in a seismogram at a given distance, for the necessary figures must be based on the maximum amplitude in a seismogram recorded at an epicentral distance of $100 \mathrm{~km}$. No such seismograms from deep-focus earthquakes have been written in southern California. Consequently, the main advantage of the magnitude scale for shallow shocks-that it is originally based on empirical data only-would not exist for deep-focus shocks.

From the point of view of the geologist and geophysicist it seems best by far to define the magnitude in such a way that two earthquakes of the same magnitude have the same energy, regardless of depth. For this, the theory employed to determine the magnitude of shallow shocks by using the true ground amplitudes of body waves (Gutenberg, 1945) can be applied without change. Equations (1), (2), and (3) of this previous paper are general and include the focal depth $h$. Consequently, the resulting values of the total ground displacement and its components $u$ (horizontal) and $w$ (vertical) of one wave, as well as the corresponding theoretical quantities $U$ and $W$ (given by equation 2 in the earlier paper), are calculable functions of the focal depth.

Equation (4) of the earlier paper connects the magnitude with the energy of a shallow shock. This is now adopted as the equation defining the magnitude of deep-focus earthquakes. If better data on the energy of earthquakes lead to improved numerical coefficients in this equation for shallow shocks, the same changes must be made for deep-focus earthquakes.

Equation (5) was based on certain assumptions regarding the duration of a given phase and the ratio of the duration of the shock at the source to the period of the waves there. These assumptions are approximations only. For shallow shocks they probably are met fairly well by $\mathrm{S}$ waves, but the observations lead to corrections for $\mathrm{P}$ which were given following equation (18) in the earlier paper. There is no indication of significant differences between shallow and deep-focus earthquakes in

* Manuscript received for publication November 17, 1944. 
this respect. As a first approximation, it may be assumed that equations (5) and, consequently, (6) to (9) remain correct. It was also assumed that in using $\mathrm{P}$ waves of great deep shocks the same corrections are to be applied as in great shallow shocks.

In the application of the results to shallow shocks it was possible to find the residuals of the magnitude $M$ calculated from the amplitudes of the body waves when compared with the magnitude found from the surface waves. With deepfocus earthquakes this is not possible. It must be assumed that the average magnitude found from the theory, assuming $C=6.3$ (eq. 12 of the earlier paper) and using data from various distances, is substantially correct. Residuals relative to this average value of $M$ may then be plotted as a function of the distance $\Delta$ and the focal depth $h$, and corrections to the calculated values $U$ and $W$ as a function of $\Delta$ may be found. However, it is not possible to find corrections for errors which effect $M$ systematically as the focal depth $h$ increases.

Observations were taken from station bulletins for the period 1923 to 1939 . Data for shocks prior to 1923 frequently leave some doubt concerning the accuracy of the determination of the focal depth, and after 1939 the amplitudes of body waves were reported by very few stations, if at all. It is quite clear from the recent investigations that, whenever possible, systematic reporting of the maximum ground amplitudes and the corresponding periods of $\mathrm{P}, \mathrm{PP}$, and $\mathrm{S}$, and also of the maximum amplitudes of surface waves with periods of about 20 seconds would aid greatly in earthquake research. Station reports most useful in the present investigation can be found from the numbers of observations, $n$, in table 1 .

From the reported periods $T$ and amplitudes $u$ (total horizontal) or $w$ (vertical) of the ground displacement in microns and the calculated values of $A$ as a function of focal depth $h$ and epicentral distance $\Delta$ it is possible to find the magnitude $M$ by the same equation (18) as in shallow shocks:

$$
M=A+0.1(M-7)-\log T+\log u \quad \text { (or } \log w \text { with different } A \text { ) }
$$

with a tentative correction of $+0.1(M-7)$ for longitudinal waves.

$A$ was calculated for focal depths of 200,400 , and $600 \mathrm{~km}$. in the same way as for shallow shocks, including the previous value $C=6.3$ for all phases. The corrections to the calculated values of $A$, which finally were adopted in the tables for shallow shocks, were also added to the calculated values of $A$ in the deep-focus earthquakes; it was assumed that they are the same for a given angle of incidence which changes slightly with increasing focal depth. The resulting values of $A$ were used in drawing theoretical curves for $A$ similar to those in figures 2 to 4 .

For the calculation of the magnitude of a given deep-focus earthquake, values of $A$ corresponding to each individual observation of $\mathrm{P}$ and $\mathrm{PP}$ (both horizontal and vertical, whichever was given) and $\mathrm{S}$ (horizontal only) were interpolated from these curves. Since theoretical curves of $A$ for $\mathrm{P}$ and $\mathrm{S}$ were available for epicentral distances between about $15^{\circ}$ and $104^{\circ}$ only, and since for distances less than $15^{\circ}$ and focal depths of less than $200 \mathrm{~km}$. the amplitudes of $\mathrm{P}$ and $\mathrm{S}$ change very rapidly with $\Delta$ and $h$, three groups of data were formed: group I, all data for $\operatorname{PP}\left(\Delta>29^{\circ}\right)$ and data for $\mathrm{P}$ and $\mathrm{S}$ at distances between $15^{\circ}$ and $104^{\circ}$; group II, data for $\mathrm{P}$ and $\mathrm{S}$ at distances less than $15^{\circ}$ and focal depths of $200 \mathrm{~km}$. or more; and group III, data 
for $\mathrm{P}$ and $\mathrm{S}$ at distances less than $15^{\circ}$ with focal depths less than $200 \mathrm{~km}$. and also at distances beyond $104^{\circ}$.

From the data of group I, $M$ was calculated by means of the preceding equation (1). The average of all data for a given shock was assumed to represent the magnitude of the shock. Only shocks with more than six individual observations were selected for the calculation of residuals, taking into consideration that the standard error of one calculated value is about 0.3 or 0.4 units of the magnitude scale; with seven observations, this should give roughly 1 in 20 times an error of $1 / 4$ magnitude or more, provided there are no systematic errors in the method.

The following average residuals in group I were found (using, where available, the station corrections given in table 2 of the previous paper):

\begin{tabular}{|c|c|c|c|c|c|}
\hline & \multicolumn{2}{|c|}{$P$} & \multicolumn{2}{|c|}{ PP } & \multirow{2}{*}{$\frac{S}{\text { Horizontal }}$} \\
\hline & Vertical & Horizontal & Vertical & Horizontal & \\
\hline Average residuals. & -0.10 & +0.11 & -0.15 & 0.00 & 0.00 \\
\hline Number of data... & 200 & 356 & 107 & 168 & 455 \\
\hline
\end{tabular}

The most important result of this tabulation is the fact that, as in shallow shocks, the transverse waves in deep-focus earthquakes receive at the source approximately the same energy as the longitudinal waves. The individual deviations are about the same as those in shallow shocks. Also, as in shallow shocks, the reported vertical components are slightly too small, probably because of larger friction in small vertical instruments, as pointed out in the preceding paper.

The residuals for each station were combined to give station corrections, separately for horizontal and vertical components. These are given in table 1 . In a few instances, trace amplitudes reported by the station were used when the free period of the instrument in general was not smaller than that of the recorded waves. The following factors to convert trace amplitudes, given in $\mathrm{mm}$., to ground amplitudes in microns were applied for waves with periods smaller than the free period of the seismograph (including a factor 1.4 for average conversion to total horizontal amplitudes): Adelaide, 10; La Plata, 4; Pasadena (long-period torsion seismograph), 1.8; Perth, 6; Sydney, 100; Hong Kong, 10.

Standard errors of one observation are not included in table 1 ; for stations with averages based on more than fifteen observations they are between 0.27 and 0.40 units of $M$. In spite of the fact that the present study was based on observations covering a different period of time than that used in the investigation of shallow shocks, the agreement between the "station corrections" found in the two papers was usually so close that the second decimals were calculated and are given in table 1 . The weighted averages given in the last two columns of table 1 were used in the correction of the residuals.

For distances of less than $15^{\circ}$ and depths of $200 \mathrm{~km}$. or more (group II), curves for $A$ were drawn by interpolation between the theoretical values for $\Delta=0$ and $15^{\circ}$, and residuals were calculated. All residuals remaining after the application of the station corrections to the data of groups I and II were plotted in diagrams for 


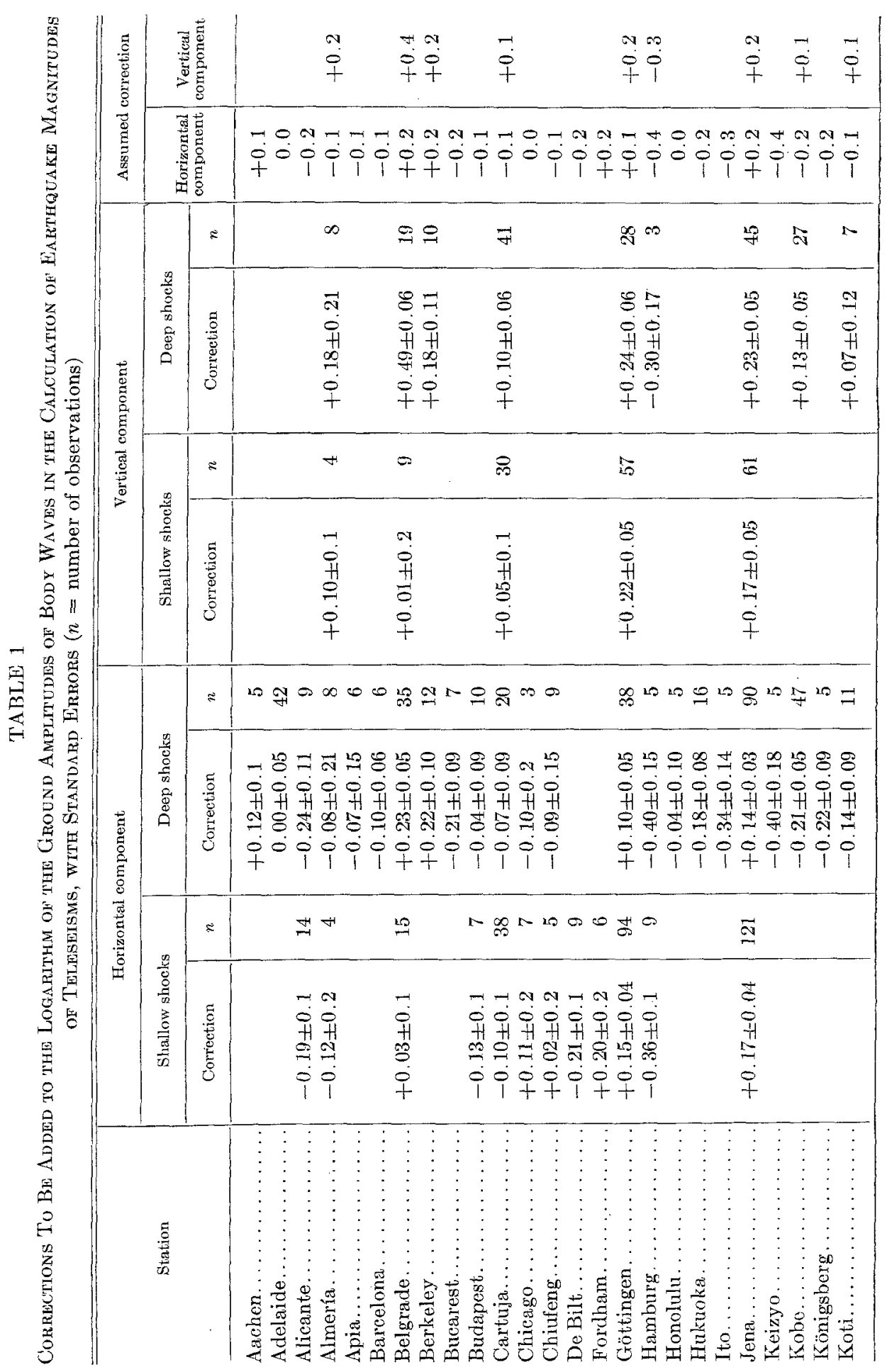




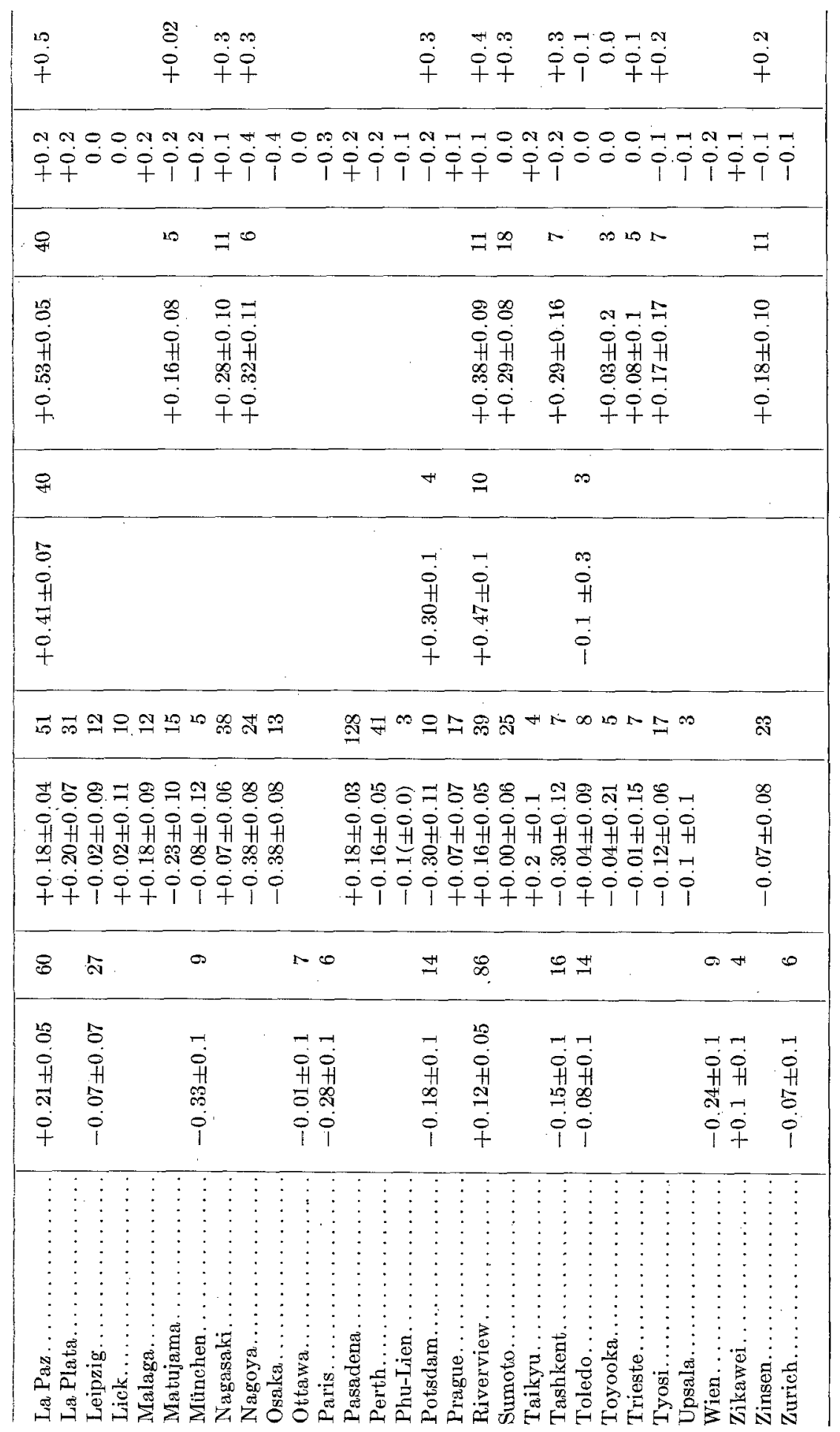




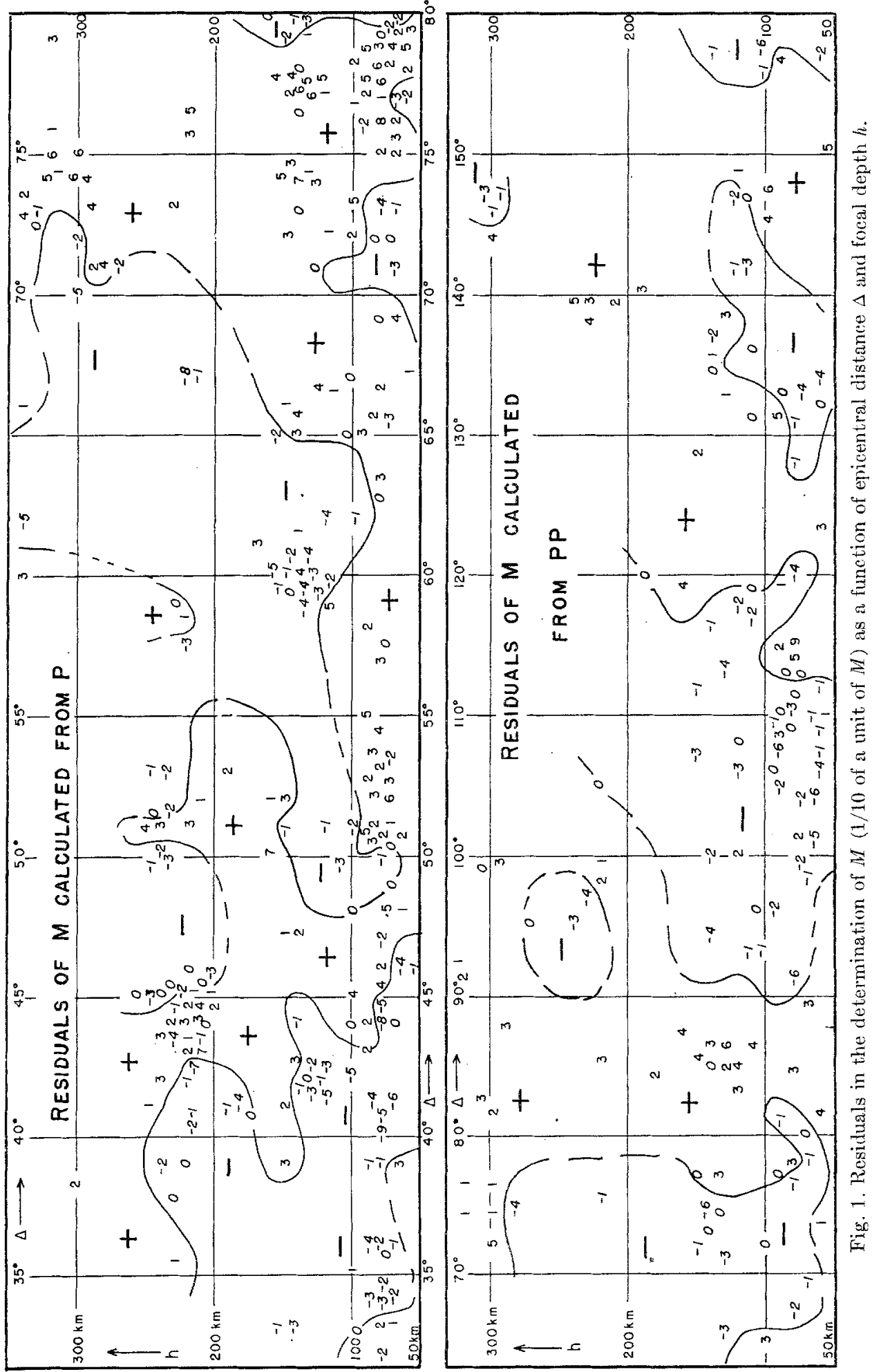


$\mathrm{P}, \mathrm{PP}$, and $\mathrm{S}$, similar to those in figure 1, including data from vertical and horizontal components. All three figures show areas where negative residuals are predominant, while others have prevailing positive residuals. The average residuals show clear similarities between $\mathrm{P}$ and $\mathrm{PP}$ at twice the distance (fig. 1). For most distances with relatively large residuals they have the same sign in intermediate shocks as found for shallow shocks in the earlier paper and indicate that corrections were applied too conservatively by the author in the earlier paper.

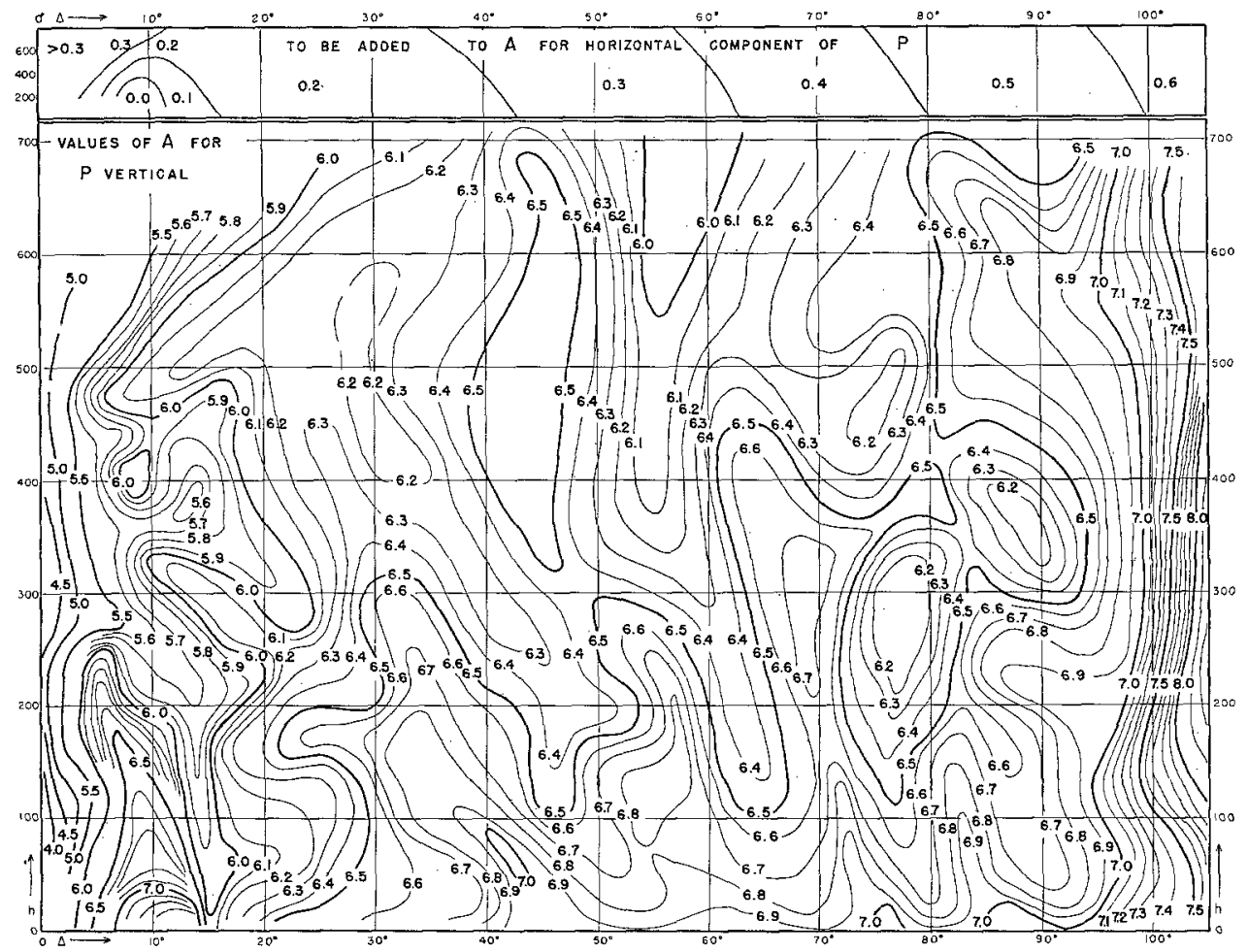

Fig. 2. Curves giving equal values of $A$ for $P$ as a function of epicentral distance $\Delta$ and focal depth $h$.

By subtracting the average residual in the neighborhood of a given point from the calculated figure, improved values of $A$ as a function of $\Delta$ and $h$ were found. These points, as well as data calculated from $M, u$ or $w$, and $T$ for group III of the observations, formed the basis for a first draft of figures 2 to 4 , giving $A$ for $\mathrm{P}$, $\mathrm{PP}$, and $\mathrm{S}$ respectively. For $\mathrm{P}$ and PP the lower part of the figures give $A$ for the vertical component; for the horizontal components of the ground displacement, the values in the upper part of the figures must be added to find $A$. For an alternative draft, individual values of $A$ were calculated from $M, T$, and $w$ (with data for $u$ corrected by means of the upper curves of figs. 2 and 3), making use of all observations. The final figures were based on both sets of curves. Together with equation (1), and the tentative correction of $+0.1(M-7)$ for $\mathrm{P}$ and $\mathrm{PP}$ in the great earthquakes, they permit the determination of the magnitude of a shock originating at any given depth $h$. 


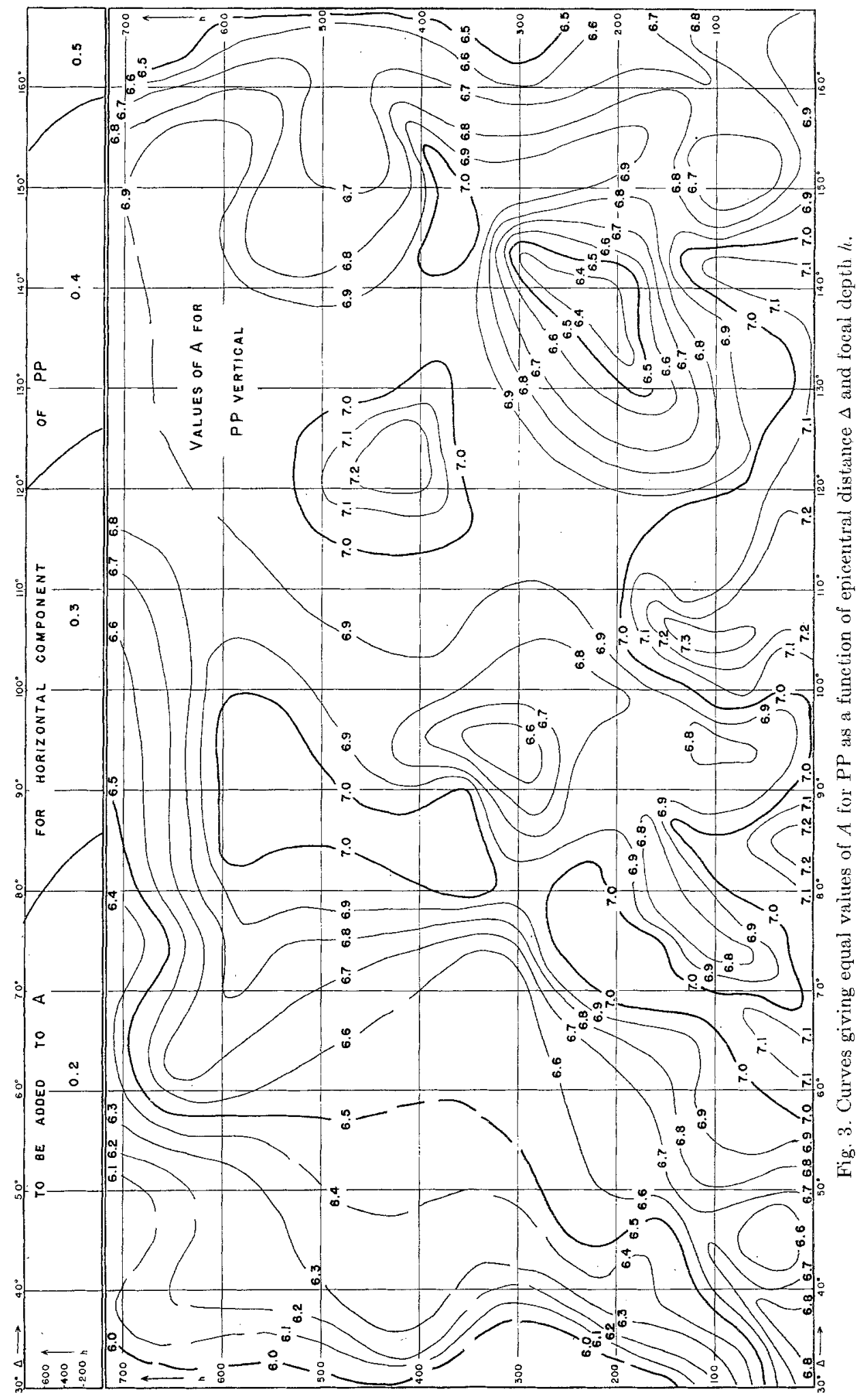


In general, the values of $A$ are probably accurate within 0.3 of a unit of $M$. In some parts of the figures, $A$ changes quite rapidly with distance; in these, the direction of the curves is close to its actual values. In other parts, $A$ changes very little with depth and distance; in such areas, the actual direction of the curves may be greatly different from that of the plotted curves. Where observations were missing, the curves were drawn to correspond with the theoretical pattern. It should be kept in mind that some peculiarities of the curves may be the result of accumulated small errors in a part of the figure for which data were scanty. In particular, when

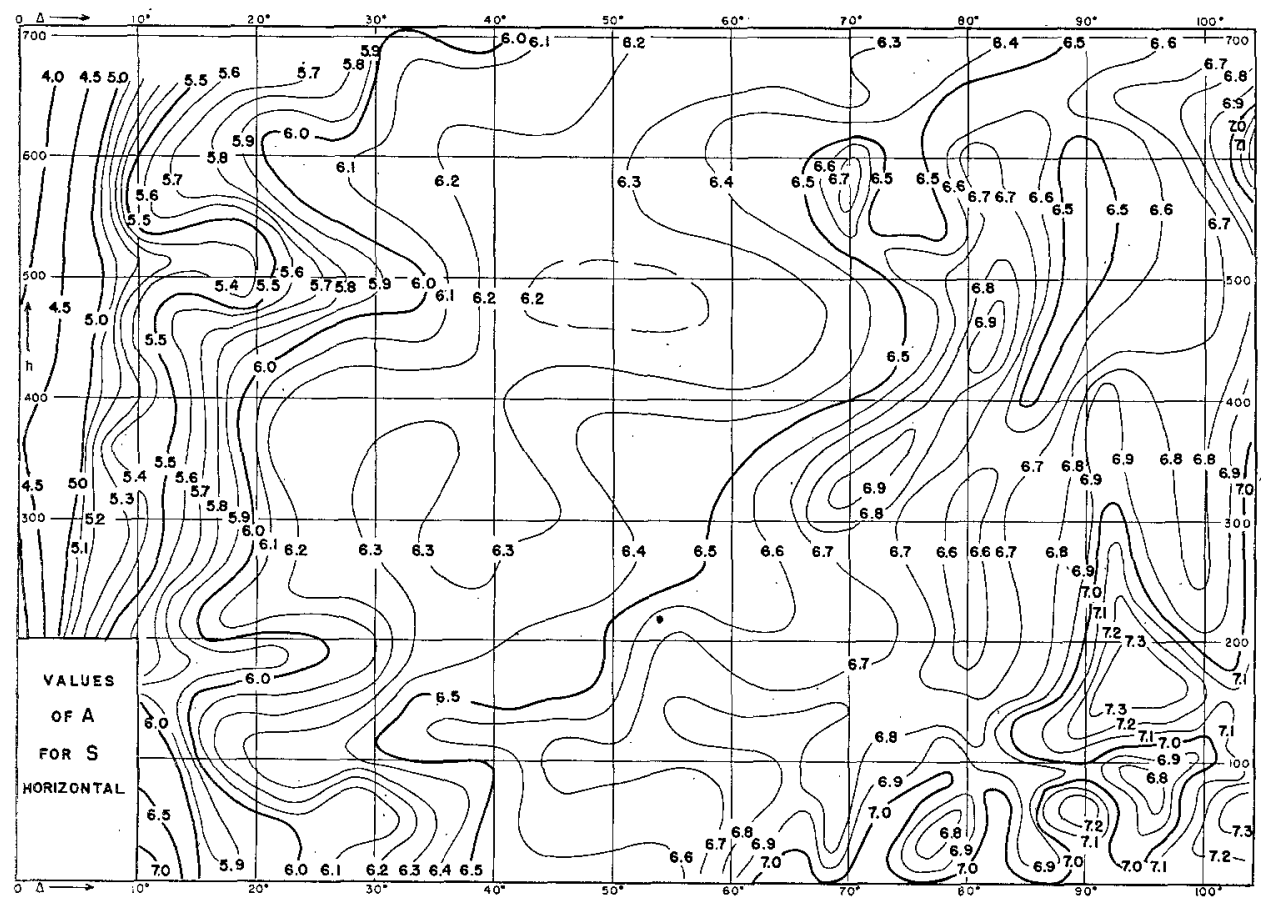

Fig. 4. Curves giving equal values of $A$ for $\mathrm{S}$ as a function of epicentral distance $\Delta$ and focal depth $h$.

an error was made in the determination of the magnitude of a shock, and no data except observations on this shock from a number of stations at about the same distance were available, a systematic error in such a part of the plot easily may have occurred, and thus a spurious "high" or "low" may have resulted.

These facts should be remembered in drawing theoretical conclusions. The pattern of figures 2 to 4 is mainly determined by two elements:

1) With increasing focal depth, less energy arrives near the epicenter, more at greater distance. The boundary between these two areas is about at that distance where the ray arrives which leaves the source horizontally (point of inflection of the travel-time curve). For greater distances, process (1) has a tendency to bend the curves for equal values of $A$ to greater distances with increasing focal depth; for smaller distances, the curves should take the opposite direction, but at these short distances the change of velocity with depth may produce effects even greater. 


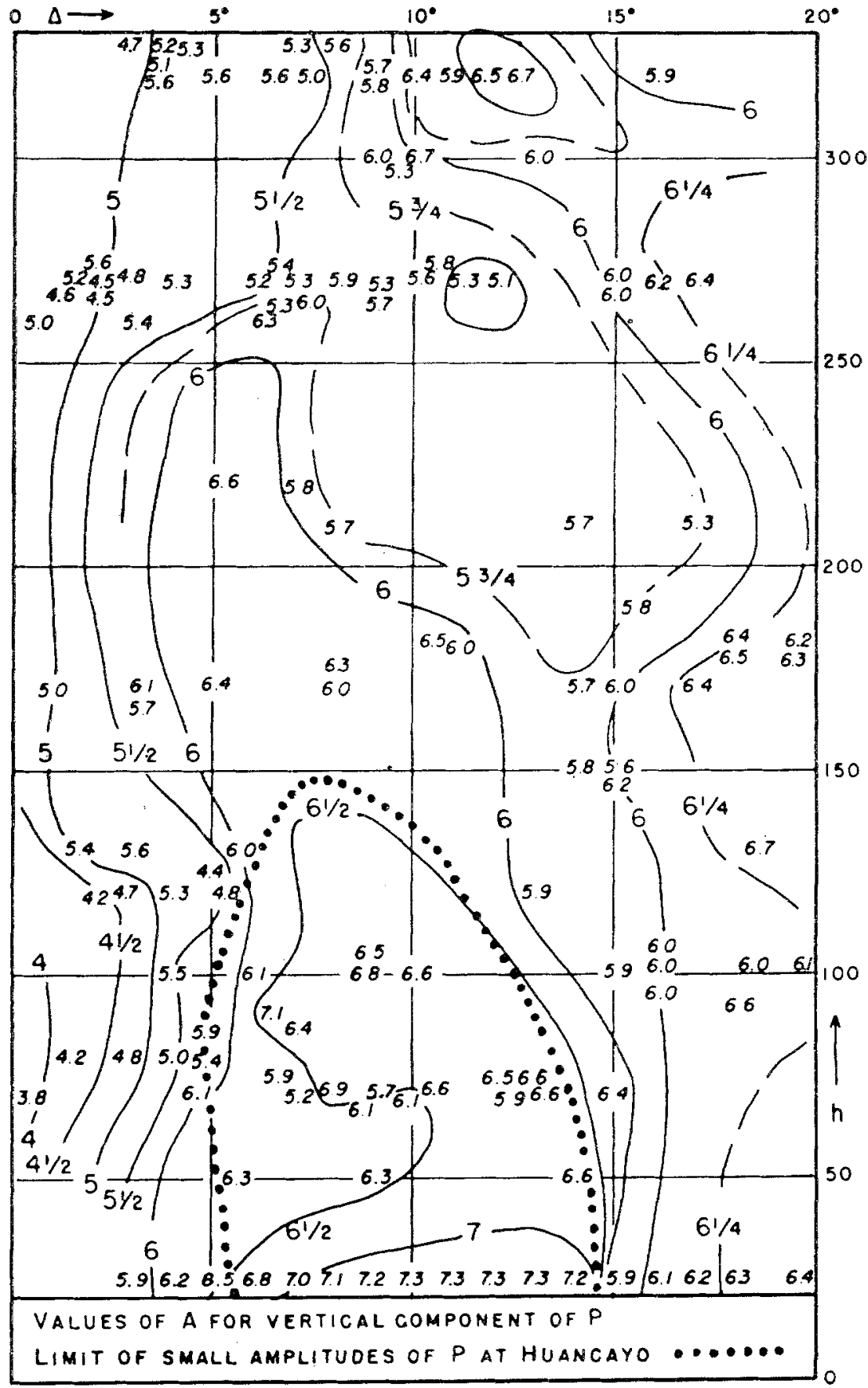

Fig. 5. Calculated values of $A$ and curves giving equal values of $A$ as a function of epicentral distance $\Delta$ and focal depth $h$. 
2) Changes of velocity with depth at the deepest point of the ray are mainly responsible for the differences in distances between the lines of equal values of $A$. Since for a shock of magnitude zero and wave periods $T$ of 0.5 sec., approximately $\log u=-A$, it is evident that relatively large values of $A$ correspond to small amplitudes of the phase under consideration. Consequently, relatively large values of $A$ indicate a relatively small increase (or slight decrease) of wave velocity with depth, near the deepest point of the ray. Theoretically, these "highs" (and "lows," corresponding to a more rapid increase in velocity with depth) should follow a direction similar to that of the dividing lines in the upper part of the figures for $\mathrm{P}$ and PP (and similarly for S). The actual pattern is the effect of the superposition of these two major and some minor phenomena.

The most outstanding pattern produced by the second type of process is the "shadow zone" for shallow and intermediate shocks at epicentral distances near $10^{\circ}$, produced by a decrease in the wave velocity slightly above a depth of $100 \mathrm{~km}$. (Gutenberg and Richter, 1939). Figure 5 shows the data for $\mathrm{P}$ on a larger scale; a curve showing the boundary between relatively large and small amplitudes at Huancayo, Peru, is added (from unpublished data of the author, extending the results in the paper by Gutenberg and Richter, 1939). In general, this curve corresponds about to $A=61 / 2$. Differences between this curve and the curve for $A=6 \frac{1}{2}$ in figure 5 may be due partly to errors, partly to the effect of different crustal structures near Huancayo and in Japan; most of the data of figure 5 are based on observations published by Japanese stations, with a few, in addition, from La Paz, La Plata, and some European stations.

There is no doubt that a similar shadow zone exists for $\mathrm{S}$, but the data are not sufficient for details. They scatter very much, and there is no doubt that in many instances amplitudes of other phases, especially surface waves in shallow intermediate shocks, are reported as those of $\mathrm{S}$.

There is a marked difference between the curves giving $A$ for $\mathrm{P}$ waves and those for $\mathrm{S}$ waves at distances beyond $100^{\circ}$. Figure 2 for $\mathrm{P}$ shows a crowding of the curves there due to the beginning of the "shadow zone" produced by the earth's core (diffracted waves). The shadow zone for $\mathrm{S}$ (fig. 4) begins at a greater epicentral distance which could not be determined exactly, as SKS, SKKS, etc., are superposed on $\mathrm{S}$. The shadow zone of $\mathrm{S}$ begins at a greater epicentral distance than that of $\mathrm{P}$ since the velocity of transverse waves increases relatively more slowly than that of $\mathrm{P}$ as the core is approached (Poisson's ratio increases). Consequently, the paths of $\mathrm{P}$ are more sharply curved than those of $\mathrm{S}$.

The amplitudes of surface waves in a shock of a given magnitude decrease with focal depth $h$ corresponding to the factor $e^{-2 \pi a h / L}$ where $L=$ wave length; the value of $a$ depends on wave type and distribution of velocity with depth (Banerji, 1925; Jeffreys, 1928; Stoneley and Tillotson, 1928). If $M$ is the magnitude of the shock determined from body waves, and $m$ the "apparent" magnitude from surface waves having a period of $20 \mathrm{sec}$. (wave length depending on the structure, roughly $L=70 \mathrm{~km}$.), then

$$
M-m=\left[2 \pi a\left(h-h^{*}\right) \log e\right] / L
$$

where $h^{*}=$ depth of a normal shock (roughly $20 \mathrm{~km}$.). Thus, approximately

$$
a=25(M-m) /(h-20)
$$


Calculated values for $a$ are given in table 2 . There are many sources of error. Even for the deepest shocks a number of stations report amplitudes for the maximum of surface waves with periods near 20 sec. Probably, in most shocks with focal depth of more than $200 \mathrm{~km}$. these maxima belong to body waves, such as SS and SSS, some of them with angular distances greater than $180^{\circ}$, or SeS, ScSScS, SPSP, etc. (See also Stoneley, 1931.) For this reason, only shocks with focal depth not

\section{TABLE 2}

Data Related to the Decreise in Ampltuddes of Surface Waves with INCREASTNG FOCAL DePTH $h$

( $M=$ magnitude of shock; $m=$ "apparent magnitude" from surface waves; no. = serial number of shocks used in earlier papers; $a=$ calculated factor, determining decrease in amplitudessee text)

\begin{tabular}{|c|c|c|c|c|c|c|}
\hline Date & No. & Region of source & $h$ & $M$ & $M-m$ & $a$ \\
\hline 1936, Juiy 13 & $23 \mathrm{e}$ & Chile. & $\begin{array}{l}\mathrm{km} . \\
60\end{array}$ & 7.3 & 0.2 & 0.1 \\
\hline 1938, wine 9 & $\mathrm{~S} 17 \mathrm{p}$ & East Indies. . . . . . & 60 & 7.2 & 0.3 & 0.2 \\
\hline 1935, Oct. 2 & $158 \mathrm{~d}$ & Kurile Is......... & 70 & 7.0 & 0.8 & 0.4 \\
\hline 1931, Mar. 28 & 89 & East Indies. . . . . . & 80 & 7.3 & 0.8 & 0.3 \\
\hline 1934, May 4 & $170 \mathrm{r}$ & Alaska.......... & 80 & 7.2 & 0.9 & 0.4 \\
\hline 1937, Sept. 3 & $170 \mathrm{~d}$ & Aleutian Is....... & 80 & 7.3 & 0.8 & 0.3 \\
\hline 1937, Sept. 15 & $76 \mathrm{~d}$ & Solomon Is........ & 80 & 7.3 & 0.7 & 0.3 \\
\hline 1934, June 13 & $158 \mathrm{~m}$ & Kurile Is........ & 90 & 6.9 & 1.0 & 0.4 \\
\hline 1937, Apr. 5 & $81 \mathrm{~s}$ & New Guinea..... & 90 & 6.9 & 0.2 & 0.1 \\
\hline 1937, July 26 & $151 \mathrm{r}$ & Japan........... & 90 & 7.1 & 0.7 & 0.3 \\
\hline 1938, Oct. 20 & $97 \mathrm{e}$ & East Indies. & 90 & 7.3 & 0.5 & 0.2 \\
\hline 1929 , Oct. 19 & 18 & Chile...... & 100 & 7.5 & 0.8 & 0.3 \\
\hline 1934 , June 24 & 16 & Chile......... & 100 & 6.9 & 0.6 & 0.2 \\
\hline 1937, July 26 & $0 \mathrm{n}$ & Mexico......... & 100 & 7.3 & 1.2 & 0.4 \\
\hline
\end{tabular}

to exceed $100 \mathrm{~km}$. were given in table 2 . For shocks with depths between 100 and $200 \mathrm{~km}$. the values calculated for a from the reported "maxima of surface waves" are between 0.1 and 0.3 .

Other errors result from the assumption $L=70 \mathrm{~km}$. for $T=20 \mathrm{sec}$. (the value of $L$ depends on the structure), from errors in the determination of $h, M$ and $m$, and from the fact that $h$ is supposed to be the depth at which the first body waves start; the maxima frequently will result from waves starting at a different depth. On the other hand, the value of a theoretically depends on the change in the velocity of shear waves with depth in the region where the surface waves are formed. Under certain assumptions, Jeffreys $(1928, p .519)$ found $a$ to be theoretically about 0.4 , but smaller values are to be expected in shocks with surface waves originating under the bottom of the Atlantic Ocean, under continental areas with relatively thin crustal layers, and especially for surface waves originating under the bottom of the Pacific Basin. The agreement between the values in table 2 and those to be expected from the theory is as good as can be expected.

A systematic investigation of the magnitude of deep-focus earthquakes is under way. The highest magnitude found thus far for a shock with a focal depth of more than $200 \mathrm{~km}$. is about $8(1906$, January $21, h=340 \mathrm{~km}$., southwest of Tokyo; 
Szirtes, 1909). The shock of 1932, May 26, $h=600 \mathrm{~km}$. south of the Fiji Islands (Brunner, 1938), had a magnitude of about $73 / 4$, and about the same magnitude was found for the shocks of 1937, April $16, h=400 \mathrm{~km}$. near the Tonga Islands, of 1909, July 7, $h=230 \mathrm{~km}$., and of 1921, November 15 (Sieberg, 1922), $h=215$ $\mathrm{km}$. in the Hindu Kush area. Several shocks with a focal depth of 70 to $200 \mathrm{~km}$. had magnitudes of $73 / 4$ to 8 , and that of 1914 , November 24 , near the Marianne Islands, focal depth about $110 \mathrm{~km}$., had a magnitude of $81 / 4$. It is the greatest intermediate earthquake which has been found thus far. The shock of 1934, June 29, $h=720 \mathrm{~km}$., in the Flores Sea, perhaps the deepest on record so far, had a magnitude of about 7 .

The author is grateful to Dr. C. F. Richter and to Mr. H. O. Woad for valuable suggestions and criticism, and to Mr. John M. Nordquist for drafting of the figures.

\section{SUMMARY}

The magnitude of deep-focus earthquakes is so defined as to make the energy released in two shocks of the same magnitude equal, regardless of focal depth.Charts are given which, in connection with the equations for the magnitude of shallow shocks, permit the calculation of the magnitude of a shock at any given depth if the maximum ground amplitude and the corresponding wave period of P, PP, or S at a given epicentral distance are known.- - It is found that the energies released in the longitudinal and transverse waves of an earthquake are about equal, regardless of focal depth.-The "shadow zone" for $\mathrm{P}$ and S waves at epicentral distances near $10^{\circ}$, indicating a slight minimum in wave velocity at a depth near $100 \mathrm{~km}$., has been confirmed, and quantitative results for amplitudes of $\mathrm{P}$ as a function of focal depth are given.--Earthquake magnitudes of $73 / 4$ to 8 have been found throughout the range of focal depths, but, during the past forty years, seem to have been relatively less frequent in deep-focus than in shallow shocks. In contrast with shallow shocks, no deep-focus earthquakes of magnitudes $81 / 4$ to $81 / 2$ have been established thus far. This indicates (but does not yet prove) that at depths of about 100 to $700 \mathrm{~km}$. roughly one-tenth as much energy can be stored as at depths of 15 to $40 \mathrm{~km}$. At a depth of about $700 \mathrm{~km}$. earthquake activity seems to stop abruptly.-The amplitudes of surface waves in deep-focus shocks decrease with increasing focal depth approximately as given by the theory.

\section{List OF REFERENCES}

BANERJX, S. K.

1925. "On the Depth of Earthquake Focus," Phil. Mag., 49:65-80.

Brunater, G. I.

1938. "The Deep Earthquake of May 26, 1932 near the Kermadec Islands," Gerlands Beitr. z. Geophysik, 53:1-64.

Gutenberg, B.

1945. "Amplitudes of P, PP, and S and Magnitude of Shallow Earthquakes," Bull. Seism. Soc. Am., 35:57-69.

GUTENBERG, B., and C. F. RIChTER

1939. "New Evidence for a Change in Physical Conditions at Depths near 100 Kilometers," Bull. Seism. Soc. Am., 29:531-537. 
JEFFREYS, H.

1928. "The Times of Transmission and Focal Depths of Large Earthquakes, ${ }^{12}$ Mon. Not. Roy. Astron. Soc., Geophys. Suppl., 1:500-521.

Richter, C. F.

1935. "An Instrumental Earthquake Magnitude Seale," Bull. Seism. Soc. Am., 25:1-32.

Steberg, A.

1922. "Mitteilungen der deutschen Erdbebenwarten sowie einiger Auslandsstationen über die Aufzeichnungen des Bebens vom 15. November 1921." Hauptstation für Erdbebenforschung in Jena.

Stoneley, R.

1929. "On Deep-Focus Earthquakes," Gerlands Beitr. z. Geophysik, 29:417-435.

Stoneley, R., and E. Tillotson

1928. "The Effect of a Double Surface Layer on Love Waves," Mon. Not, Roy. Astron. Soc., Geophys. Suppl., 1:521-527.

SzIRTES, S.

1909. "Seismogramme des japanischen Erdbebens am 21. Januar 1906," Veröff. Zentralbureaus Internat. Seismol. Assoz., Ser. A. Strassburg, 50 pp., 7 pl.

California Institute of Technology,

Pasadena, Calimornia.

(Balch Graduate School of the Geological Sciences, Contribution no. 379) 